\title{
Accelerating Research Innovation by Adopting the Lean Startup Paradigm

\author{
Kaisa Still
}

\author{
"It is the unlikely partnership between academia, the public" \\ sector and private enterprise that allow us to navigate the \\ path from discovery, to innovation, to transformation. The \\ process, however, is often unwieldy, taking decades to go \\ from primary discovery to a measurable impact on society. \\ Greg Satell \\ Innovation advisor and author \\ In Forbes, Dec. 18, 2015
}

\begin{abstract}
Converting scientific expertise into marketable products and services is playing an increasingly important role in the launching of new ventures, the growth of existing firms, and the creation of new jobs. In this article, we explore how the lean startup paradigm, which validates the market for a product with a business model that can sustain subsequent scaling, has led to a new process model to accelerate innovation. We then apply this paradigm to the context of research at universities and other research organizations. The article is based on the assumption that the organizational context matters, and it shows how a deeper understanding of the research context could enable an acceleration of the innovation process. We complement theoretical examples with a case example from VTT Technical Research Institute of Finland. Our findings show that many of the concepts from early-acceleration phases - and the lean startup paradigm - can also be relevant in innovation discussions within the research context. However, the phase of value-proposition discovery is less adequately addressed, and that of growth discovery, with its emphasis on building on a scalable, sustainable business does not seem to be addressed with the presented innovation approaches from the research context. Hence, the entrepreneurial activities at the research context differ from those in startups and internal startups in established organizations.
\end{abstract}

\section{Introduction}

Today, commercialization, or "going to market" (Friedman, 2002), is particularly challenging, especially given the pressure to do it quickly. Indeed, it has been claimed that the need for speed in development and speed in going to market have a tremendous impact on the dynamics of technology transfer and is the most important driver of change, which means that a firm's ability to develop and market products and technologies quickly is crucial (Amesse \& Cohendet, 2001).

However, the context of this study is the research world, which is not oftentimes characterized as a dynamic environment with a high clock-speed, though it has been stated that "in the long run, only dynamic and innovative research environments survive" (Graversen,
2007). For example, some years ago, it was estimated that it takes three to six months to put a research team together; hence, this long-term perspective that is needed for several design iterations can only be achieved by government funding (Nunamaker, cited in Winter, 2010). A bit more than a third of all R\&D activities in Europe continue to be funded by government (Eurostat, 2016). Reaping the benefits of product and service innovation - in a timely, successful manner, continues to be a challenge. In Europe, a so-called European paradox has been acknowledged, referring to the perceived failure of European countries to translate scientific advances into marketable innovations (European Commission, 1995). Furthermore, the European Commission has placed renewed emphasis on the conversion of Europe's scientific expertise into marketable products and services by seeking to use 


\section{Accelerating Research Innovation by Adopting the Lean Startup Paradigm}

\section{Kaisa Still}

public sector intervention to stimulate the private sector and to remove bottlenecks that stop such ideas reaching the market (Eurostat, 2016).

Technology transfer - simply defined as "the movement of know-how, technical knowledge, or technology from one organizational setting to another" (Roessner, 2000) - from universities and other public research organizations is increasingly seen to play a significant role in contributing to new venture creation, the growth of existing firms, and new job creation. This role is oftentimes addressed under the umbrella concept of innovation, which for about 20 years has been viewed as a complex, interactive process that is essentially systemic in character (Autio, 1997), with technology transfer activities loosely regarded as "boundary spanners" or "brokers" between academia and industry (O'Kane et al., 2015).

In this article, we seek to transfer a technology innovation methodology from industry to academia. By applying the "lean startup" paradigm to research activities of universities (and other public research institutions), we seek to accelerate innovation in a research context. The article is structured as follows. First, we briefly examine the lean startup paradigm and share insights about innovation in the research context. Then, we introduce a new model of innovation acceleration developed specifically to address the European paradox of commercialization failure. Next, we align our innovation acceleration model with theories and methods from the research context and share practical insights from a case from VTT Technical Research Centre of Finland. We then discuss the findings, and we conclude by highlighting the implications for researchers, managers, and policy makers.

\section{Lean Startup Paradigm}

The lean startup paradigm envisions a new company arising based on a new product or service that will be embraced by a particular market (Maurya, 2012; Ries, 2011) because it solves the customer's urgent problem (Moogk, 2012). Simply put, the paramount goal of the startup management team is to find product/market fit with a business model that can scale before they run out of cash (Blank 2014). It has been stated that the uniqueness of this lean startup methodology consists of its ability to explicitly take into account the numerous uncertainties regarding the sustainability and suitability of a given solution towards a specific customer problem (Rasmussen \& Tanev, 2015).
The ideas behind the lean startup were launched by the introduction of the customer development process by Steve Blank (2007). Subsequently, it has been refined by Blank to emphasize experimentation (Blank, 2013), with the focus on the adaptiveness and effectiveness of new startups in dealing with the scarcity of resources in their go-to-market efforts (Maurya, 2012). Around the same time, Erik Ries (2011) tied the lean startup concept to lean manufacturing and lean thinking by applying them to the context of entrepreneurship. He wrote the game-changing book The Lean Startup: How Constant Innovation Creates Radically Successful Businesses, which is based on five principles that guide the translation of a specific entrepreneurial vision into new products and solutions:

\section{Entrepreneurs are everywhere.}

\section{Entrepreneurship is management.}

3. Learning should be validated.

4. Follow a build-measure-learn approach.

5. Apply innovation accounting: a qualitative approach that allows entrepreneurs to see whether the innovation engine is working.

In the lean startup, the first part of the innovation process is to determine whether the product vision can be matched with a problem worth solving using a combination of qualitative customer observation and interviewing techniques (Maurya, 2012). If the product vision is validated with customer data (i.e., if there is a problem/solution fit), the startup rapidly builds prototypes or initial versions of its product that are complete enough to demonstrate the value it brings to the users. This is known as a minimum viable product (MVP) (Moogk, 2012). Once the problem is found and the MVP is built, the goal of a startup is to validate that there is an attractive enough market for the solution. In effect, the startup is looking for a viable business model. Throughout this process, learning can take place, supporting the question whether to pivot the original strategy or persevere (Ries, 2011).

Ries (2011) further states that the lean startup must avoid doctrines and rigid ideology. Some have labelled lean startup "a movement" (Rasmussen \& Tanev, 2015) as well as "a collection of tools and techniques that can be employed by entrepreneurs to build their ventures faster and at lower cost" (Harms, 2015), both emphasiz- 


\section{Accelerating Research Innovation by Adopting the Lean Startup Paradigm}

\section{Kaisa Still}

ing that it tends to be viewed more as a practice-based methodology than a theory for innovation. However, Harms (2015) points out that innovation and technology management scholars may know the lean startup approach under the names of "disciplined entrepreneurship", "hypothesis-driven entrepreneurship", or "probe and learn".

\section{Innovation in a Research Context}

\section{The importance of context}

In a special issue focusing on the importance of context in entrepreneurial innovation, Autio and colleagues (2014) state: "All human action occurs in contexts: it is the context that regulates what individuals and teams get to see, what choices they are likely to make, what the outcomes of those choices are likely to be. For this reason, context must play a central role in our understanding of the origins, forms, micro-processes, functioning, and diverse outcomes of entrepreneurial activities." They go on to acknowledge and emphasize the tendency in the entrepreneurship literature to focus on the individual, the team, and the resulting venture while neglecting the context.

Still, earlier research has emphasized that the environment in which an individual works is likely to have a great influence on that individual's behaviour, with the main environmental factors being culture, policies, and routines (Kalar \& Antoncic, 2015). The research streams that have concentrated on contexts explaining entrepreneurial innovation have explored nations, regions, and industries - and, according to these scholars, context matters because it shapes not only the opportunities that are available but also the dynamics that unfold (Garud et al., 2014). Hence, the research context as such has not been a dominant research stream, though universities and public research organizations have been presented as key players in knowledge ecosystems, advancing technological innovation within the system (Clarysse et al., 2014).

The boundaries between science and business are blurring (O'Kane et al., 2015), as evidenced by the introduction of concepts such as "academic capitalism", the "triple-helix", and the evolving entrepreneurial university. By extending the role of universities beyond simply producing new knowledge, but also disseminating this knowledge to industry and society, the entrepreneurial university is expected to provide a culture and suitable atmosphere for encouraging academics through activities that are more entrepreneurial in nature (Kalar \& Antoncic, 2015). Still, the contrast is clearly acknowledged: the startup culture "encourages individual initiative and autonomy, and creates a shared esprit de corps that results in the passionate and relentless pursuit of opportunity. This is the antithesis of the process, procedures and rules that make up large companies" (Blank, 2014).

In his seminal work focusing on university-directed commercialization and entrepreneurial innovation at Stanford University, Nelson (2014) showed how the organizational context not only shaped the decision to engage in entrepreneurship but also the specific approach taken to the commercialization process. In Nelson's work, interviewees argued that the availability of specific funding sources influenced the specific commercialization focus and urgency. Furthermore, he finds it doubtful that individual initiatives such as faculty workshops on entrepreneurship, access to technical equipment, or a seed grant in the tens of thousands of dollars (all common approaches taken by universities in their attempts to spur entrepreneurship) would have changed the fundamental commercialization process and its impact.

Nelson (2014) hence suggested that understanding entrepreneurial behaviours may demand attention not only to individual-level characteristics but also to contextually-informed approaches to action. In addition, he advises that it might be good to embrace those aspects of the university context that mark it as distinct from the firm - for it might be these very features that plant and nurture the research that leads to future marketable technologies.

\section{Understanding innovation in a research context}

In the 1980s and 1990s, the focus of technology transfer was on competiveness and was based on a rather simple logic: universities and government labs make, industry takes (Bozeman, 2000). In introducing the concept of design science for the research context of information systems, the purpose was to produce systems that do not yet exist, to achieve better results, with an engineering emphasis (Nunamaker et al., 1991). The concept of "the last mile" was introduced to identify where the value to society is created: the last mile is where you make the lasting difference (Nunamaker et al., 2015; Winter, 2010). This is seen to proceed in three stages: i) proof-of-concept research to demonstrate the functional feasibility of a solution; ii) proof-of-value research to investigate whether a solution can create value across a variety of conditions; and iii) proof-ofuse research to address complex issues of operational feasibility. This means that the solution is not really un- 


\section{Accelerating Research Innovation by Adopting the Lean Startup Paradigm}

\section{Kaisa Still}

derstood and cannot really be evaluated before it is actually implemented, and researchers cannot predict the impact of their research when only sitting at their desks (Nunamaker et al., 2015).

In the late 1990s, Autio (1997) discussed new technology-based firms emerging as spinoffs from universities and public research organizations. He saw some key differences between science-based firms (firms developing applications concerning physical phenomena or theoretical constructs) and engineering-based firms (firms expanding the scope of use of these applications), arguing that the dominant focus of sciencebased firms was on a technology-push mode of technology transfer, whereas the emphasis of engineeringbased firms appeared to be on a market-pull mode. However, according to Autio, ultimately the most important economic impact of these spinoffs may well be as a catalyst delivered through technology interactions between the firms and their operating environment.

In the 2000s, the research context was addressed by introducing the term "public research institutions". In 2007, a paper suggested two modes of innovation: the science, technology, and innovation (STI) mode, which is based on the production and use of codified scientific and technical knowledge, and the doing, using, interacting (DUI) mode, which relies on informal processes of learning and experience-based know-how (Jensen et al., 2007). It also argued - just like Autio did 10 years earlier - that, in most areas, the results of scientific research are not directly useful for technological advances. Rather, they are more about providing guidance and clues for further development. Furthermore, it suggested that firms with an exclusive focus on developing their science and technology base could benefit from adopting practices and measures designed to promote informal learning by DUI. For public research institutions and universities, it was pointed out that, if they cannot foster sufficient commercialization and entrepreneurial skills among their academics and technology transfer officers, it may be appropriate to place more emphasis on licensing inventions. Hence, in technology transfer, patenting and subsequent licensing were still heavily favoured.

In the 2010s, the linkages between science, technology, and university spinoffs and universities were increasingly emphasized. In explaining their multi-stage, holistic model for creating university spinoffs, Pattnaik and Pandey (2014) argued that universities are moving from their traditional roles of research, teaching, and knowledge dissemination into a more advanced role of creating spinoffs and promoting academic entrepreneurship, with significant impact on regional development and economic growth. They highlighted the role of spinoffs as significant engines toward the commercialization of the technologies that were previously developed, but they also noted that university researchers tend to be more focused in technology development than in other equally important aspects of business. Pattnaik and Pandey's (2014) model consisted of four steps: i) competences and funding; ii) test and confirmation of results; iii) invention disclosure and patenting; and iv) creating spinoffs, leasing technology, and focusing on general economic and social value. More recently, Boh and colleagues (2016) stated that faculty and students are most heavily involved in the earliest phases of the technology commercialization process of the university spin-offs. These authors also identified six stages in the early technology commercialization process: i) idea generation; ii) the commercializing decision; iii) prototype generation and establishment of commercial and technical viability; iv) founding team formation; v) strategy and commercialization process determination; and vi) fundraising to sustain activities, with the aim of convincing investors that the new technology has commercial and technical viability (Boh et al., 2016).

On the research organization side - now addressed as public research organizations - Steinmo and Rasmussen (2016) concluded that they play a crucial role in $R \& D$ and innovation across a wide range of industries. On one hand, public research organizations are seen as valuable collaboration partners; firms that collaborate with public research organizations are more likely to develop innovations than other firms. On the other hand, most firms find it difficult to collaborate with public research organizations. Business organizations and public research organizations are seen to pursue different goals. They are therefore structurally different from each other in many ways such as, for example, in their incentive structures and management styles (Steinmo \& Rasmussen, 2016). These differences often prevent firms from using public research organizations as sources of external information, and firms generally rate them very lowly as information sources and potential partners.

\section{An Innovation Acceleration Model Inspired by Lean Startup}

In many public research organizations, research projects have been undertaken to address the European paradox. Indeed, this has also been a starting point for 


\section{Accelerating Research Innovation by Adopting the Lean Startup Paradigm}

\section{Kaisa Still}

the Accelerate project (www.accelerateproject.eu), which is part of the second instalment of the ITEA programme (itea3.org) to support innovative, industry-driven, precompetitive $R \& D$ projects in the area of software-intensive systems and services. Overall, the project is focused on enabling: i) the commercialization of better products and services, ii) while being faster to the market, and iii) with sustainable business models. During the project, a new model of innovation acceleration has been developed to overcome some of the key limitations of current models of innovation. Most existing models represent some variations on the familiar pipeline-process architecture: they are not embedded in the strategy issues of company boards, and hence there is misalignment between the newly emerging theoretical models of innovation and innovation in practice (Berkhout et al., 2010).

Inspiration for the model of innovation acceleration has been found from the new kind of innovation thinking that has emerged from within the startup world. The principles of lean startup entrepreneurship have been extended beyond the startup context as the earlystage entrepreneurial challenges have been found to exist beyond the context encountered by typical hightechnology ventures (Lockett et al., 2005). The "internal startup" concept, in which a company launches a separate (semi-)independent initiative to pursue a new innovation or idea (Mäkijärvi et al., 2016), has even been claimed so successful that "an internal startup is an ideal environment to nurture innovation and entrepreneurship in large companies" (Edison et al., 2016).

The resulting innovation acceleration model has been defined with four phases (customer discovery, solution discovery, value proposition discovery, and growth discovery), moving from the initial idea to the scalable, fast-growing, and sustainable business (Figure 1). The customer discovery phase aims at producing an initial concept: a vision for a new business with committed people. The solution discovery phase aims at a highvalue concept with user acceptance and resources to move forward. In the value proposition discovery phase, a validated and desired solution is produced

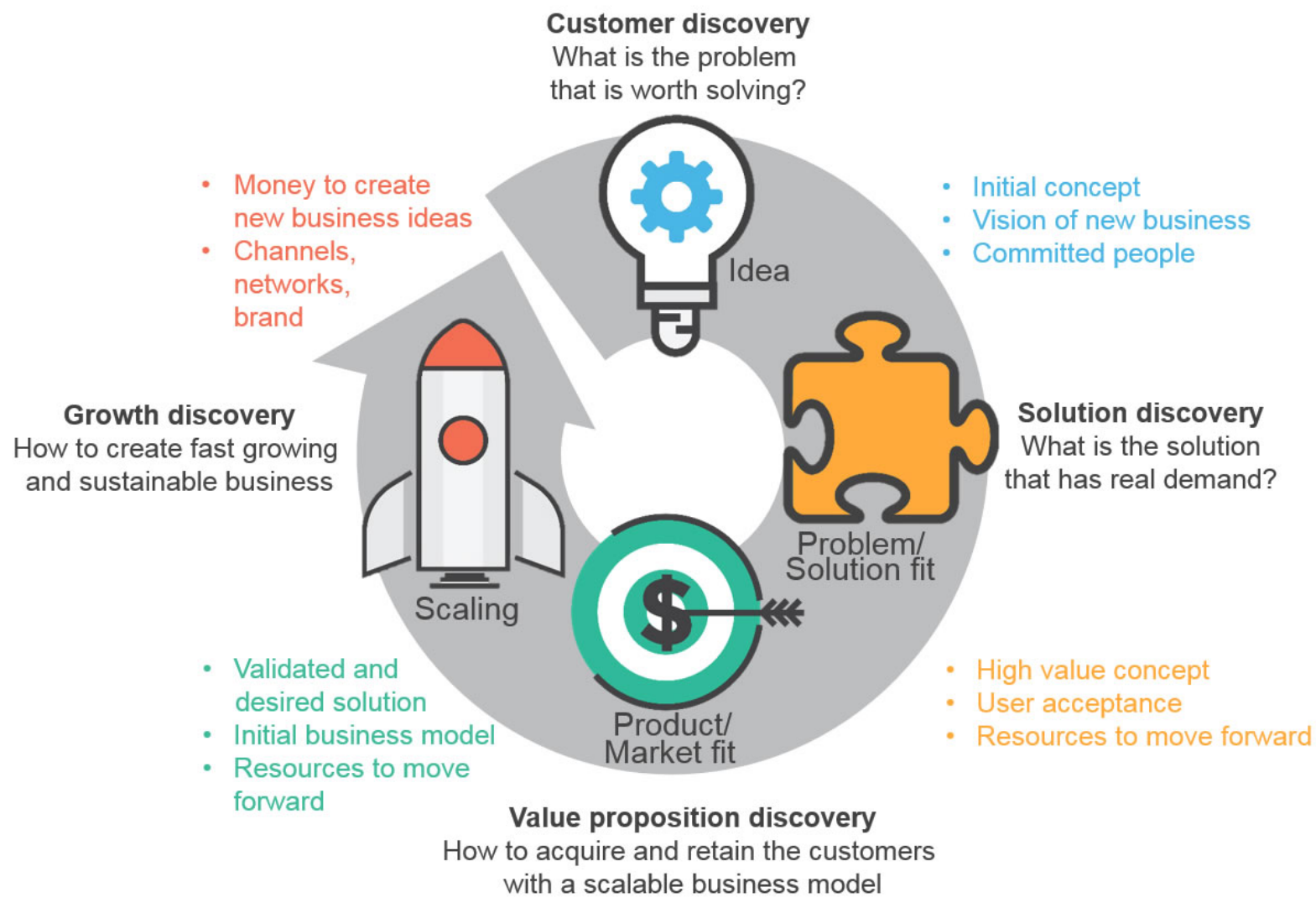

Figure 1. The innovation acceleration model 


\section{Accelerating Research Innovation by Adopting the Lean Startup Paradigm}

\section{Kaisa Still}

with an initial business model and resources to move forward. The growth discovery phase is about scaling and creating a sustainable business, which then is expected to result in money to create new business ideas, as well as channels, networks, and brand. Hence, it is a model of continuous refinement, in which especially the two last phases are go-to-market activities as the entity is operating in the market with its value proposition, going toward scaling.

The new process model has been validated by working with Finnish startups that could easily place themselves within the continuum of the process elements (Wallin et al., 2015). It has been successfully used by some of startups and internal startups of the Accelerate project. It has been also used in European startup masterclasses (Mohout, 2014).

\section{Applying the Innovation Acceleration Model to the Research Context}

This article is based on the premise that, in today's fastpaced world faced with global competition, it is imperative for many stakeholders to explore the opportunities for accelerating innovation in the research context. Hence, we set out to answer the following research question: How can the innovation acceleration model be applied in the context of research?

As described above, it is well known that the research context (referring to universities and research organizations, especially public research organizations) differs from the context of business. Overall, it has been stated that traditional research projects focus on exploration while startups focus on exploitation (Nelson, 2014). Furthermore, in academia, it has been stated that ideas are generated for their own sake, and their implementation is considered less important or even irrelevant (Winter, 2010). For the purpose of this article, we have selected and presented some perspectives that would be relevant in highlighting the differences in innovation acceleration. Still, in this so-called non-commercial environment, speed has been proven to matter (Lockett et al., 2005).

Our research is less about the entrepreneurial individuals - although we understand that innovation in all of its phases is done by individuals - and more about the organizational context. We agree, therefore, with the hypothesis that organizational context plays a role in shaping how participants approach technology commercialization (Autio et al., 2014; Nelson, 2014). We seek to explore the extension of the possibilities of innovation acceleration beyond standalone startups and internal startups.

To explore the importance of context for innovation, and innovation acceleration in particular, we analyzed a selection of different approaches. These approaches, representing more than 20 years of innovation research in a research context, were categorized and mapped onto the schematic representation of the innovation acceleration methodology, which, as already presented, is very much based on the lean startup paradigm.

\section{Context of a case study}

After aligning our innovation acceleration framework with theories and methods from the research context, we sought to derive complementary practical insights by applying it within VTT Technical Research Centre of Finland Ltd (vttresearch.com). VTT is a leading research and technology company in the Nordic countries, and it offers research and innovation services to both private and public partners. In 2015, it had a net turnover of $185 \mathrm{M} €$, received 48 new patent applications, and created 21 spinoffs.

Recently, VTT has been re-focusing its strategy by focusing on growth: with scientific and operational excellence, it wants to bring its own innovations to the market, simultaneously supporting Finnish companies and society on the whole. The new strategy journey supports the analysis of the existing innovation and technology transfer processes such as the one made for the purposes of this article. There are a number of improvement projects under way, for example related to intellectual property rights, sales and spinoffs, service model development, as well as a wider implementation of the lean startup methodology. It should be noted that spinoffs are not new to VTT: Autio's (1997) early research into technology-based new business creation included 29 VTT spinoffs.

As just one example of VTT's innovation activities, the Innovative Business from Emerging Technologies (iBet) program encourages internal startups and internal entrepreneurship within VTT. It explores future opportunities, concentrating on renewing the technology basis and leading to societal, industrial, and technological impacts. VTT is looking for great ideas that can be incubated, refined, and transformed into inventions, further developing them into innovations aiming at marketable products, solutions, and services. The iBet programme proceeds as follows: 


\section{Accelerating Research Innovation by Adopting the Lean Startup Paradigm}

\section{Kaisa Still}

1. For selected ideas, team members are invited to spend $3-5$ days to prepare a pitch.

2. Teams with successful pitches are given one month for further development.

3. Approved plans are given funding for one year, with an option for further continuation.

From 2016 to 2017, 168 ideas were submitted to the iBet process. Of these, 20 ideas were selected, 13 of which were granted funding for one year.

\section{Findings}

With the aim of understanding the applicability and use of the lean startup paradigm within the research context, the research question was explored using both the theoretical approaches as well as one concrete case. The findings are presented in Table 1, which shows how the four phases of the innovation acceleration model are addressed.

The major finding of the analysis is that the front-end of the model is addressed by all of the approaches. However, the "go-to-market" elements corresponding to the two last phases of the innovation model are not widely addressed. The value proposition discovery phase was oftentimes presented as something that another entity than the university or research organization, such as a spinoff, would take care of. The phase of growth discovery, with its emphasis on building on scalable, sustainable business does not seem to be addressed with the presented innovation approaches from the research context.

The first phase of customer discovery encourages entrepreneurs (or entrepreneurial teams) to create an initial concept and vision of new business with selected committed people. This phase responds to the tensions of market pull versus technology push with developing applications and technology interactions (Autio, 1997) and the doing-using-interacting model (Jensen et al., 2007). This phase also emphasizes the competences and funding from the creating of spinoff model (Pattnaik \& Pandey, 2014) as well as idea generation, the commercialization decision, and founding team formation of the early technology commercialization process at universities (Boh et al., 2016).

The second phase is about solution discovery, when the goal is to create a high-value concept, with user accept- ance and resources to move forward. The proof-ofconcept and proof-of value (Nunamaker et al., 1991) and the continuation of doing-using-interacting (Jensen et al., 2007) can be placed into this phase. Also, the test and confirmation (Pattnaik \& Pandey, 2014), and the prototype generation and establishment of commercial and technical viability as well as invention disclosure and patenting (Boh et al., 2016) correspond to this phase.

In the third phase of value proposition discovery, developing a validated and desired solution is key, with corresponding efforts to create the initial business model, and again, with resources to move on. The proof-of use (Nunamaker et al., 1991) correlates to the validated solution. Whether to move on with a spinoff or with leasing technology (Pattnaik \& Pandey, 2014) can be seen as creating an initial business model - however, again, taking the innovation process outside of the university or research organization setting, and hence forcing the innovation acceleration cycle to start from the beginning. The strategy and determination of the commercialization process as well as fundraising to sustain activities (Boh et al., 2016) also can be seen to be part of this third phase. However, whether all of these activities create a high-value concept is to be determined, as many of the research context approaches do not mention user acceptance or real contact and feedback from customers, which is imperative in the lean startup paradigm.

The fourth phase, growth discovery, aims at creating scalable, sustainable businesses. Other than with the hint that spinoffs or licensing agreements are the tools for taking the innovation to the market, it does not seem to be addressed with the innovation approaches discussed in the research context. Channels, networks, and brands are not mentioned in the descriptions of these approaches, nor is the business sustainability focusing on securing the money to create a new business.

VTT's approach to supporting entrepreneurship with the iBet program also reflects the phases of the acceleration methodology, and shows how the lean startup paradigm is increasingly being applied to the research context. Idea selection corresponds to the idea phase, development of plans corresponds to the problem/solution fit, and continued funding allows for exploring toward the product/market fit. Again, the words "scaling", "brand", and "growth" are note mentioned in the iBet program, and hence the growth discovery phase does not appear to be addressed. 


\section{Accelerating Research Innovation by Adopting the Lean Startup Paradigm}

\section{Kaisa Still}

Table 1. Mapping the innovation in research context to the model for innovation acceleration

\begin{tabular}{|c|c|c|c|c|}
\hline \multirow[b]{2}{*}{$\begin{array}{l}\text { Innovation in Research } \\
\text { Context }\end{array}$} & \multicolumn{4}{|c|}{ Innovation Acceleration Model } \\
\hline & $\begin{array}{l}\text { Customer Discovery } \\
\text { What is the problem } \\
\text { that is worth solving? }\end{array}$ & $\begin{array}{l}\text { Solution Discovery } \\
\text { What is the solution } \\
\text { that has real } \\
\text { demand? }\end{array}$ & $\begin{array}{l}\text { Value Proposition } \\
\text { Discovery } \\
\text { How to acquire and } \\
\text { retain the customers } \\
\text { with a scalable business } \\
\text { model }\end{array}$ & $\begin{array}{l}\text { Growth Discovery } \\
\text { How to create fast } \\
\text { growing and } \\
\text { sustainable business }\end{array}$ \\
\hline $\begin{array}{l}\text { Nunamaker et al. (1991) } \\
\text { Nunamaker et al. (2015) }\end{array}$ & - & $\begin{array}{l}\text { - Proof-of-concept } \\
\text { - Proof-of-value }\end{array}$ & - Proof-of-use & - \\
\hline Autio et al. (1997) & \multicolumn{2}{|c|}{$\begin{array}{l}\text { - Developing applications } \\
\text { - Market pull } \\
\text { - Technology interactions }\end{array}$} & - & - \\
\hline Jensen et al. (2007) & \multicolumn{2}{|c|}{$\begin{array}{l}\text { - Doing-Using-Interacting } \\
\text { (DUI model) }\end{array}$} & - & - \\
\hline Pattnaik \& Pandey (2014) & $\begin{array}{l}\text { - Competences } \\
\text { and funding }\end{array}$ & $\begin{array}{l}\text { - Testing and } \\
\text { confirmation of } \\
\text { results } \\
\text { - Invention disclosure } \\
\text { and patenting }\end{array}$ & \multicolumn{2}{|l|}{$\begin{array}{l}\text { - Creating spinoffs } \\
\text { - Leasing technology }\end{array}$} \\
\hline Boh et al. (2016) & $\begin{array}{l}\text { - Idea generation } \\
\text { - Commercializatio } \\
\text { n decision } \\
\text { - Foundingteam } \\
\text { formation }\end{array}$ & $\begin{array}{l}\text { - Prototype generation } \\
\text { and establishment of } \\
\text { commercial and } \\
\text { technical viability } \\
\text { - Strategy and } \\
\text { commercialization } \\
\text { process } \\
\text { determination }\end{array}$ & $\begin{array}{l}\text { - Fundraising to } \\
\text { sustain activities, } \\
\text { with the aim of } \\
\text { convincing investors }\end{array}$ & - \\
\hline VTT Case: iBET & - Idea selection & $\begin{array}{l}\text { - Development of } \\
\text { selected plans }\end{array}$ & $\begin{array}{l}\text { - Continued funding } \\
\text { for selected plans }\end{array}$ & - \\
\hline
\end{tabular}

\section{Discussion}

Universities and research organizations, identified as non-commercial environments, oftentimes with commercialization and go-to-market activities going through technology transfer offices, have been described with their specific innovation activities, characteristics, and processes, hence separating them from companies and businesses. For example, new techno- logy-based firms have been described as growth oriented, taking risks to pursue growth, growing or perishing with their technology (Autio, 1997), and none of those descriptions were found in the research innovation literature.

Still, it can be concluded that many of the innovationrelated concepts derived from the research context can be fitted into the acceleration methodology. However, 


\section{Accelerating Research Innovation by Adopting the Lean Startup Paradigm}

\section{Kaisa Still}

it is also evident that the context does make a difference, and that the research context has been approaching innovation from a different perspective. The descriptive exploration of more than 20 years of innovation activities within a research environment indicated the impact of context on entrepreneurial activities $\mathrm{Au}-$ tio et al., 2014; Clarysse et al., 2014; Garud et al., 2014; Nelson, 2014). Hence, our results from analyzing innovation approaches from a research context with the model for innovation acceleration bring evidence to the notion that entrepreneurial innovation is profoundly affected by its context (Autio et al., 2014).

Some of the principles of the lean startup approach (Ries, 2011) could be found in the analyzed innovation approaches. For example, the doing, using, interacting (DUI) model as well as informal learning (Jensen et al., 2007) correspond very well to the overall idea of validated learning. The research context is seen to be moving from exploration to exploitation (Nelson, 2014) hence, going toward the goal of a successful business, which is at the core of the lean startup paradigm, and indeed, Pattnaik and Pandey (2014) already mention spinoffs as the means for that. However, with this creation of spinoffs as well as with leasing technology, Pattnaik and Pandey (2014) move the innovation process away from the university or research organization setting. Hence, research organizations are seen to be valuable partners in innovation (Steinmo \& Rasmussen, 2016), perhaps with the implicit connotation that they are not actual innovators and entrepreneurs, which conflicts with the first lean startup principle: "entrepreneurs are everywhere" (Ries, 2011). In addition, the emphasis on the user (or market) is not dominant in the research context approaches. For example, the multi-stage, holistic model of creating university spinoffs (Pattnaik \& Pandey, 2014) does not seem to focus on user needs. Also, discussions of management or innovation accounting were not directly addressed in the selected approaches.

The practical example from VTT, the iBet program, can be seen as one way of going beyond the traditional innovation process of a research organization. Although it also showed that the growth discovery phase was notably not included, it did include some emphasis on goto-market activities. Furthermore, the fact that this entrepreneurship focused program was attractive to the personnel at VTT is interesting and encouraging: with the total number of VTT researchers at about 1450, this translates to submission from more than 11 percent of them (assuming that each researcher only submitted one idea). This finding reflects that the research context (at least in Finland) is changing, and entrepreneurship is increasingly seen to be part of it.

\section{Limitations of the study}

Innovation continues to be a multi-disciplinary topic with a large amount of literature related to its processes, characteristics, impact, etc. This article does not pretend to be comprehensive in its quest to analyze how the lean startup paradigm explicitly presented with an innovation acceleration methodology can be applied in the context of research. Rather, the article is intended as more of an exploratory discussion that starts from an existing model for innovation acceleration, and its applicability and validity in the research context. Hence, the number of research approaches analyzed was limited, and the approach was aligned with a single case example from VTT. In particular, the major finding of the "go to market" elements corresponding to the two last phases of the innovation model but especially on the growth discovery/scaling being largely absent from the research context could be explored further, with more examples as well and on the basis of a more thorough theoretical review.

\section{Managerial implications}

There are many different actors in the research context who are involved in the innovation process. Beyond research personnel, new business development people, intellectual property specialists, and early sales professionals, accelerating innovation is important to all. All of us must know the terminology and the process steps that are generally used to describe innovation within our specific contexts. However, we should not feel limited by the semantic framework, especially if the organization wants to go beyond traditional plans and development activities, and really starts "doing, using, and interacting".

As the early phases of innovation are increasingly emphasized in research contexts, research organizations should start addressing this gap by adopting lean startup practices. The adaptation of competence development, hiring practices, and strategic partnering are also possible methods in developing go-to-market capabilities by taking into account the different early stages of the research process context. With the new capabilities, the issue of speed can also be addressed.

Looking into the demand side of technology and innovation is also encouraged. Going beyond the traditional technology transfer is emphasized by Blank (2014), who states that companies manage innovation by building innovation internally, buying it, or partnering with re- 


\section{Accelerating Research Innovation by Adopting the Lean Startup Paradigm}

\section{Kaisa Still}

sources outside of the company. It should be noted that he heavily emphasizes the acquisition of startups as the corporate innovation strategy, which is also supported by the evidence of growth strategies of companies such as Google. A question worth exploring in more detail hence becomes: will startups become the de-facto standard for technology transfer from research to the corporate world?

\section{Policy implications}

Innovation policy has not been immune to the paradigm shift the lean startup: it sees the promise of successful businesses that will contribute to wealth, competitiveness, and quality of life. Not only are the results of lean startups on the wish list, but so are the ingredients. For example, Finland wants to become an international leader in experimental culture, at both national and regional levels as well as in organizations (kokeilevasuomi.fi/en/frontpage). Accordingly, the Finnish government has continued to develop research funding programs that focus on and support experimentation.

This article highlights the interdependencies of the research context's innovation process with the surrounding innovation ecosystem, and the impacts created by such activities. This aspect was also emphasized by Autio and colleagues (2014): "the connections and ties across these specific contexts are crucial for entrepreneurial innovation and future policy development deeds to recognize these inter-dependencies and the possible synergies and conflicts between them." For example, the innovation policy has direct links to customer needs; the speed of knowledge transfer is partly controlled by the scientific publishing processes.

At the same time, the impact of context on an individual's innovation activities is emphasized. For example, to put it bluntly, it may be detrimental to expect the same kind of entrepreneurship from scientists at research organizations as from individuals working at startups.

Overall, there is a clear call for clarity of roles and responsibilities of various ecosystem players and for addressing the dynamics of such systems. Also, the value of having these players coming from various contexts and still co-creating together should be further studied.

\section{Conclusion}

In this article, we conducted a limited literature review to highlight that the research context was seen to have its own innovation characteristics and processes for technology transfer. We then explored how the lean startup paradigm explicitly presented as an innovation acceleration model matched the special context of research. The concepts from research innovation were complemented with a practical example: the iBet case at VTT Technical Research Institute of Finland.

The findings show that many of the concepts of the early acceleration phases can also be found in the innovation discussions within the research context. The phases for going-to-market receive less attention: i) the value proposition discovery phase was addressed sometimes, and even then, it was oftentimes presented that another entity than the university or research organization such as a spinoff would take care of it; and ii) the phase of growth discovery, with its emphasis on building on scalable, sustainable business does not seem to be addressed with the presented innovation approaches from the research context.

Hence, the entrepreneurial activities at the research context differ from those in startups and internal startups, which supports the impact of context presented, for example, by Nelson (2014) and Autio and colleagues (2014). This gap should be discussed and addressed at research organizations, for example with practical tools for competence development, hiring, and the selection of strategic partners. Furthermore, when looking into the demand-side of the technologies and innovation, there seems to be an inclination to emphasize startups as means of technology transfer. If this continues, it challenges not only the culture and processes but also the outputs of the research context. In addition, policy makers should take this into account when clarifying the roles, responsibilities, value-creation activities, and dynamics within the innovation ecosystem.

\section{About the Author}

Kaisa Still is a Senior Scientist at VTT Technical Research Centre of Finland. She has extensive experience of innovation management gained within a research organization and a university, in a startup and in growth companies, as well as in a business incubator. Supporting collaboration, co-creation and innovation with technology continues to be at the core of her interests. Her current work concentrates on platforms and innovation ecosystems, accelerating innovation activities, and digital opportunities. Combined with the policy perspective, her work extends to private and public organizations, in regional and global contexts. 


\section{Accelerating Research Innovation by Adopting the Lean Startup Paradigm}

\section{Kaisa Still}

\section{References}

Amesse, F., \& Cohendet, P. 2001. Technology Transfer Revisited from the Perspective of the Knowledge-Based Economy. Research Policy, 30(9): 1459-1478.

https://doi.org/10.1016/S0048-7333(01)00162-7

Autio, E. 1997. New, Technology-Based Firms in Innovation Networks Symplectic and Generative Impacts. Research Policy, 26(3): 263-281.

https://doi.org/10.1016/S0048-7333(96)00906-7

Autio, E., Kenney, M., Mustar, P., Siegel, D., \& Wright, M. 2014. Entrepreneurial Innovation: The Importance of Context. Research Policy, 43(7): 1097-1108.

https://doi.org/10.1016/j.respol.2014.01.015

Berkhout, G., Hartmann, D., \& Trott, P. 2010. Connecting Technological Capabilities with Market Needs Using a Cyclic Innovation Model. R\&D Management, 40(5): 474-490. http://dx.doi.org/10.1111/j.1467-9310.2010.00618.x

Blank, S. 2007. The Four Steps to Epiphany: Successful Strategies for Products that Win. Raleigh, NC: Lulu Enterprises.

Blank, S., 2013. Why the Lean Start-up Changes Everything. Harvard Business Review, 91(5): 635-72.

Blank, S. 2014. Corporate Acquisitions of Startups - Why Do They Fail? Forbes, April 22, 2014. Accessed April 21, 2017: https://www.forbes.com/sites/steveblank/2014/04/22/corporateacquisitions-of-startups-why-do-they-fail/

Boh, W. F., De-Haan, U., \& Strom, R. 2016. University Technology Transfer through Entrepreneurship: Faculty and Students in Spinoffs. The Journal of Technology Transfer, 41(4): 661-669. http://dx.doi.org/10.1007/s10961-015-9399-6

Bozeman, B. 2000. Technology Transfer and Public Policy: A Review of Research and Theory. Research Policy, 29(4-5): 627-655. https://doi.org/10.1016/S0048-7333(99)00093-1

Clarysse, B., Wright, M., Bruneel, J., \& Mahajan, A. 2014. Creating Value in Ecosystems: Crossing the Chasm between Knowledge and Business Ecosystems. Research Policy, 43(7): 1165-1176. https://doi.org/10.1016/j.respol.2014.04.014

Edison, H., Wang, X., \& Abrahamsson, P. 2016. Product Innovation through Internal Startup in Large Software Companies: A Case Study. Paper presented at the 42nd Euromicro Conference on Software Engineering and Advanced Applications (SEAA), Limassol, Cyprus, August 31 - September 2, 2016.

https://doi.org/10.1109/SEAA.2016.36

Eurostat. 2016. R\&D Expenditure. Eurostat: Statistics Explained. Accessed April 21, 2017:

http://ec.europa.eu/eurostat/statistics-

explained/index.php/R_\%26_D_expenditure

Friedman, L. G. 2002. Go To Market Strategy: Advanced Techniques and Tools for Selling More Products, To More Customers, More Profitably. Oxford, UK: Butterworth-Heinemann, Elsevier Science.

Garud, R., Gehman, J., \& Giuliani, A. P. 2014. Contextualizing Entrepreneurial Innovation: A Narrative Perspective. Research Policy, 43(7): 1177-1188.

https://doi.org/10.1016/j.respol.2014.04.015
Graversen, E. B. 2005. Dynamic Research Environments: A Development Model. The International Journal of Human Resource Management, 16(8): 1498-1511. http://dx.doi.org/10.1080/09585190500220754

Harms, R. 2015. Self-Regulated Learning, Team Learning and Project Performance in Entrepreneurship Education: Learning in a Lean Startup Environment. Technological Forecasting \& Social Change, 100: 21-28.

https://doi.org/10.1016/j.techfore.2015.02.007

Jensen, M. B., Johnson, B., Lorenz, E., \& Lundvall, B. Å. 2007. Forms of Knowledge and Modes of Innovation. Research Policy, 36(5): 680-693. https://doi.org/10.1016/j.respol.2007.01.006

Kalar, B., \& Antoncic, B. 2015. The Entrepreneurial University, Academic Activities and Technology and Knowledge Transfer in Four European Countries. Technovation, 36-37: 1-11. https://doi.org/10.1016/j.technovation.2014.11.002

Lockett, A., Siegel, D., Wright, M., \& Ensley, M. D. 2005. The Creation of Spin-Off Firms at Public Research Institutions: Managerial and Policy Implications. Research Policy, 34(7): 981-993. https://doi.org/10.1016/j.respol.2005.05.010

Märijärvi, J., Hokkanen, L., Komssi, M., Kiljander, H., Xu, Y., Raatikainen, M., Seppänen, P., Heininen, J., Koivulahti-Ojala, M., Helenius, M., \& Järvinen, J. 2016. The Cookbook for Successful Internal Startups. Helsinki: Digile, N4S. http://www.n4s.fi/wordpress/wpcontent/uploads/2016/04/the_cookbook_for_successful_Internal_s tartups.pdf

Maurya, A. 2012. Running Lean: Iterate from Plan A to a Plan That Works, 2nd Ed. Sebastopol, CA: O'Reilly Media Inc.

Mohout, O. 2014. Startup Master Class 1 - Genesis: Idea Stage. Antwerp: Antwerp Management School. http://www.slideshare.net/omohout/genesis-43234459

Moogk, D. R. 2012. Minimum Viable Product and the Importance of Experimentation in Technology Startups. Technology Innovation Management Review, 2(3): 23-26. https://timreview.ca/article/535

Nelson, A. J. 2014. From the Ivory Tower to the Startup Garage: Organizational Context and Commercialization Processes. Research Policy, 43(7): 1144-1156. https://doi.org/10.1016/j.respol.2014.04.011

Nunamaker, J. F., Chen, M., \& Purdin, T. D. M. 1991. Systems Development in Information Systems Research. Journal of Management Information Systems, 7(3): 89-106. http://dx.doi.org/10.1080/07421222.1990.11517898

Nunamaker, J. F. Jr., Briggs, R. O, Derrick, D. C., \& Schwabe, G. 2015. The Last Research Mile: Achieving Both Rigor and Relevance in Information Systems Research. Journal of Management Information Systems, 32(3): 10-47.

http://dx.doi.org/10.1080/07421222.2015.1094961

O'Kane, C., Mangematin, V., Geoghecan, W., \& Fitzgerald, C. 2015. University Technology Transfer Offices: The Search for Identity to Build Legitimacy. Research Policy, 44(2): 421-437. https://doi.org/10.1016/j.respol.2014.08.003 


\section{Accelerating Research Innovation by Adopting the Lean Startup Paradigm}

Kaisa Still

Pattnaik, P. N., \& Pandey, S. C. 2014. University Spinoffs: What, Why, and How? Technology Innovation Management Review, 4(12): 44-50.

https://timreview.ca/article/857

Rasmussen, E. S., \& Tanev, S. 2015. The Emergence of the Lean Global Startup as a New Type of Firm. Technology Innovation Management Review, 5(11): 12-19.

https://timreview.ca/article/941

Ries, E. 2011. The Lean Startup. New York: Crown Business.

Roessner, J. D. 2000. Technology Transfer. In C. Hill (Ed). Science and Technology Policy in the US: A Time of Change. London: Longman.

Steinmo, M., \& Rasmussen, E. 2016. How Firms Collaborate with Public Research Organizations: The Evolution of Proximity Dimensions in Successful Innovation Projects. Journal of Business Research, 69(3): 1250-1259.

https://doi.org/10.1016/j.jbusres.2015.09.006

Wallin, A., Still, K., \& Komi, M. 2015. Start-Up Entrepreneurs' Key Concerns on Path of Entrepreneurial Innovation. In Proceedings of the XXVI ISPIM Conference - Shaping the Frontiers of Innovation Management, Budapest, Hungary, June 14-17, 2015.

Winter, R. 2010. Interview with Jay F. Nunamaker, Jr. on "Toward a Broader Vision of IS Research". Business \& Information Systems Engineering, 2(5): 321-329.

http://dx.doi.org/10.1007/s12599-010-0122-8

Citation: Still, K. 2017. Accelerating Research Innovation by Adopting the Lean Startup Paradigm.

(cc) BY

Technology Innovation Management Review, 7(5):

32-43. http://timreview.ca/article/1075

Keywords: innovation, innovation acceleration, research, research organization, innovation paradox, lean startup, context, VTT, commercialization 